\title{
Situational Influence of Competitions and Competitors in Strategic Communication Design
}

\author{
Jacob Udayi Agba \\ Department of Mass Communicatıon, Faculty of Communıcatıon Technology, \\ Cross River Unıversity of Technology, Calabar, Nıgeria \\ James U. Effiom \\ Publıc Relations Department, Cross River University of Technology, Calabar, Nıgeria
}

\section{Doi:10.5901/ajis.2015.v4n1p11}

\begin{abstract}
This paper is intended to show the situational influence of competition and competitors in strategic communication. We assume in this paper that situations have influence on competition and competitors and as such, the manager, communicator and all those involved in promoting organizational goals and interests, must design communication strategies that could help in packaging the intended message, using the right approach, appropriate words and the desired media in delivering the message. In a competitive environment, message selection is very necessary, if the needed impact and result must be achieved. Using four selected telecommunication service providers in Nigeria, we critically examined strategic communication designs among competitors in competitive environment and proposed other persuasive approaches to enhance strategic communication designs. Comparative analytical rhetoric approach to the discussion was adopted. The paper concludes that designing the right communication strategy is the right approach in the realisation of tangible results in a competitive environment. It therefore, recommends that since every situation can possibly influence competition/competitors, developing rightful communication strategies must not be taken for granted.
\end{abstract}

Keywords: Situational Influence, Strategic Communication, Competitive Environment, Persuasion and Business Accomplishment

\section{Introduction}

According to Sambe (2008,p.2), communication is "the medium through which relationships are established, extended and maintained. It provides a means by which those in business, politics and other professions act, exchange information and ideas, develop plans, proposals and policies make decisions and manage people and materials".

In view of the above, the issue of communication must be taken very seriously, because it is the bed-rock for successful business accomplishments. This is more so that, in a competitive environment, every situation counts, and it determines the necessary or needed message to get the desired result(s).

This means that in developing the communication message, the required strategy must be sought for; the situation must be taken into consideration as well as the target audience. This way, one will be able to survive the weight of competitors and the competition techniques.

Every situation creates either positive or negative effect. This variables are quite dependent on the communication methods put in place. This consideration is necessary even in ordinary situations. If that be the case, then in a competitive environment, made up of competition/competitors, greater care must be taken in ensuring that all necessary communication strategies are put to use if there must be good result or survival.

The competitor must be conscious of his/her competitors and the competitive environment, in packaging the message or in designing the communication methods or strategies. All approaches must be at his/her disposal in determining suitable messages that can possibly meet the need(s) of the target audience. If the right approach is not employed, it would have a negative effect, and other competitors may take advantage of that to his/her detriment.

Therefore, it is of utmost importance to evaluate the message content, bearing in mind the competitive environment, the purpose of the message, the target audience as well as the expected result(s). 


\subsection{Objective and Approach to the Narrative}

The objective of this paper, therefore, is to first, use selected Nigerian telecommunication service providers to critically examine strategic communication designs in competitive environment and to propose appropriate strategic communication designs for different competitions and competitors. To realize this objective, we adopt comparative analytical rhetoric as research approach to the discussion. This method is necessary in order to address as many competitive communication situations as possible and the different ways of enhancing such communication strategies.

\subsection{Theoretical Framework}

There are a number of theories on persuasion. But for the purpose of this paper, social Judgment Theory will be used. The social judgment theory posits that an attitude is a much more complex matter than is suggested by binary descriptions such as "favourable-unfavourable" or "positive-negative". It sees attitude change as a two-stage process; the receiver first judges the attitude and then makes the necessary adjustments.

According to this theory, an attitude is better viewed as a continuum with gradations ranging from "most acceptable" or "most unacceptable". The areas covering these gradations are known as "latitudes": a latitude of acceptance, that is, positions a person finds acceptable, a latitude of non-commitment, that is, positions about which the person is neutral or undecided, and a latitude of rejection, positions the person finds decidedly unacceptable. Therefore, the person's ability to persuade others on a given topic is dependent on where the topic falls on the attitude continuum of the person to be persuaded. If it falls within his/her latitude of non-commitment, in which case he/she is not "egoinvolved", the person will have little difficulty in going along with the persuasive message. If it falls within his/her latitude of rejection, in which he/she is "ego-involved", the person is likely to resist the persuasive message, seeing it as more discrepant to his own attitude than it actually is. On the other hand, where the message falls within his/her latitude of acceptance, the person easily accept the persuasive message, viewing it as more congruent with his/her attitude than it actually is.

It therefore follows that it would be much more difficult to persuade a person on a topic in which he/she is egoinvolved than on the one in which his/her ego is not involved. The level of difficulty would differ directly with the level of ego-involvement. Therefore, a would-be persuader would be well advised to first ascertain where the pertinent topic falls on the attitude continuum of the person to be persuaded. This would help the persuader to select or design messages that are most likely to create persuasive or strategic communication effect.

\subsection{Conceptual Modeling}

It is quite imperative to define the terms in this paper to enable us grasp the understanding of the work. This is because a clearer idea of the concept here will help the work to have a direction that would be of immense benefit in the event of further research or enquiry into the topic. That is why it is necessary to explain each of the concepts in the topic under review.

\subsubsection{Situational Influence}

The concept, situational influence gives one the idea that every situation creates impact and may be necessary or responsible for certain action(s). A particular situation may be responsible for a particular action.

For example, under normal circumstances, supply is dependent on demand. When there is increase in demand for a particular commodity or product, the situation will affect supply. That is, there will equally be increase in supply for that product and verse versa. So the situation that there is increase in the demand for that product has influenced the state of supply for that same product.

Also, in planning for a particular communication message, the situation on ground is likely to influence the packaging of the message, if the intended result or objective will be achieved. Even in adopting a market strategy, the situation on ground will influence the necessary method that would be considered if the intent is to achieve result.

So situational influence means that what is at present affects what is to be done or is done. Situations create impact or effect. 


\subsubsection{Competition and Competitors}

Competition gives rise to competitors and verse versa. Competition is a situation where there are two or more people doing a particular job or services. For example, there is competition in the GSM business in Nigeria. This is because there are more than one network service providers in existence.

Competitors have to do with those that are involved in the competition. Those doing the same kind of job or rendering the same kind of services are the competitors. We still use the example of the network service providers in Nigeria for instance, as competitors. We have MTN, Glo, Etisalat and Airtel as GSM network service providers in Nigeria. They are all providing network services to the people of Nigeria. So they are seen as competitors.

The primary aim of competitors is to compete for excellence. Each competitor wants to stand taller and stronger than his/her opponent. The slogans of the four major mobile phone networks in Nigeria today for instance, attest to this:

The slogan of airtel is "Come Alive With Airtel"; while Etisalat network says, "Now You are Talking". For Globacom network, the slogan is "Rule Your World"; while the slogan of the MTN says, "Everywhere You Go". All the slogans are strategically designed with other competing networks in mind. For example, with the airtel network saying, "come Alive with Airtel", the network is saying that it is the network more interested in connecting rural Nigeria to the mobile phone as it was the first to make significant inroad into the rural areas. With Etisalat saying, "Now you are Talking", , the network is expressing her pride in helping to bring down the mobile phone tariffs in Nigeria. When Globacom says, "Rule Your World", the network is saying in comparison to other networks, its services are better in terms of reliability and quality. By MTN network saying, "Everywhere You Go", it is saying that it is the largest network in Nigeria. Competition and competitors create rivalry among themselves and they also create choice(s) for the consumer. They play a very vital role in determining the communication strategy that may be necessary at a given time or situation.

\subsubsection{Strategic Communication Design}

Strategic communication is a situation where the communicator looks for the best or appropriate means of packaging his/her message in such a way that the intended result or aim is achieved.

Every situation has its own peculiar communication strategy and until this is taken into consideration, set goals or objectives may not be realised. Because of this, it is obvious to developing the appropriate communication strategy for the appropriate results.

Strategic communication then has to do with planning, designing or packaging an appropriate message at a particular time or situation that will bring or create the desired impact, thus realising the desired or intended objective. It has to do with the coming up of the needed message or communication plan toward the realisation of set goals.

\subsection{How Situational Influence of Competition and Competitors Affect Strategic Communication Design.}

From the analysis or explanation of the concepts in this paper, it becomes easier for one to understand to what extent situational influence of competition and competitors can affect strategic communication design.

Competition and competitors create situations that can possibly affect or determine how a particular communication strategy could be planned or developed. That is, knowing the different businesses that exist and those involved in them is a necessary ingredient for fashioning or designing the appropriate message for desired results.

Market forces, nature of businesses, business environment and the operators of businesses are key players in deciding what message to adopt, how to package it and the means of methods of delivery the same. In deciding this also, the type of audience(s) is also given utmost consideration. This is because each of these cannot be ignored when strategic communication design, if the necessary objectives must be achieved.

According to Gene (2005: p. 27), "Strategic communication is a competitive weapon. The tone of business and government has changed. With limited resources everyone is forced to strategically focus on outcomes and results". He stresses that strategic communication is a "must do", and no longer a "nice to do".

With fewer contracting opportunities, a shift towards lowest cost, technically acceptable procurements, and pressure to in source services, companies that live on government business must re-visit and sharpen their messages, to ensure relevancy with the current political and cultural environment. They must demonstrate cost-savings and performance metrics. To do this, messages from proposals to the company website must consistently and clearly communicate the company's value and differentiators.

Strategic communication is the new Mantra. Executives are talking about the importance of strategic 
communication, whether in reference to the need for transparency, improving services, recruiting employees, ensuring consolidated programmes are successfully integrated or launching a new cloud solution. Strategic communication happens because goals are set, success metrics are determined, target audiences are identified, messages are developed and appropriate communication channels are efficiently use to communicate a consistent message.

Strategic communication design must be in line with current or prevailing situational determinants occasioned by competition and competitors. This way the communication mode is effective and set goals are realised.

\section{Types of Communication Strategies Required when Dealing with Competition/Competitors}

According to Wilson (2005: p.62), "the simplicity or complexity of communication activity or process is dependent on the simplicity or complexity of the organisation". This explains that communication strategies differ, depending on what/who is involved.

As explained by Sambe (2008,p.2), "communication is the medium through which relationships are established, extended and maintained. It provides a means by which those in business, politics and other professions act, exchange information and ideas, develop plans, proposals and policies, make decisions and manage people and materials".

In view of the vital role communication plays in human life, it is necessary to look at some of the different communication strategies needed when dealing with competition/competitors.

Situational influence in persuasive communication effectiveness as studied by scholars like Liska, (1978); Miller and Burgoon, (1973) and others, shows that situational differences affect persuasive effectiveness. This implies that the type of relationship between the sender (source) and the receiver affects the type of message choice that can be used for maximum persuasive effectiveness. This explains that the message by the sender must be based on the understanding and cordiality with the receiver.

As mentioned earlier, every situation is likely to influence competition/competitors in strategic communication methods. For this reasons, many communication strategies have been put in place. Few of them will be considered in this work for the purpose of clarity of the subject matter under discussion.

\subsection{Compromise}

This is a very importance communication strategy that must be developed in a competitive environment. This is a situation where both the actors and targets give and take in other to achieve success. There should be mutual understanding among the different competitors in their competitive environment. To achieve this, there must be a communication strategy to bring about this. For example, there should be a message designed to bring compromise among the producers of close-up toothpaste with producers of other brands of toothpaste. This message if properly communicated will bring compromise among the producers of the different brands of toothpastes with their consumers.

\subsection{Esteem}

In planning a communication message, the worth of the target audience must be given consideration. Esteem is persuasive communication strategy intended to increase or promote the self worth of the target audience. Depending on the prevailing situation, it becomes quite necessary to design communication message(s) that will promote the self worth of the competitors in a competitive environment. This communication strategy highlights the worth of certain products and why they should be preferred to others. It also highlights the esteem of users of certain products against others. This kind of communication strategy can make the audience to start patronizing a certain product or services more than the other because of the esteem derivable from the use of such product or services.

\subsection{Explanation}

There are times where consumers do not know or understand the benefits that can be gotten for using a particular product or services. It is therefore the place of the communicator to plan a strategic message that will help explain to consumers the benefit of such a product or services to them. This message will give credibility to the product or services. Why it should be desired more than the other. Explanation communication strategy will help give a vivid explanation as to why the product or services is good for the consumers. It will give reasons based on evidence or logic why he/she should value such a product or services more than the other one in the market. 


\subsection{Moral Appeal}

Sometimes communication messages are packaged for the purpose of moral appeal. In a competitive atmosphere, there are products or services that are morally good to be consumed by members of the public against others. So in planning out a communication strategy, the moral appeal of such a product or services as highlighted will certainly bring patronage to the product or services. The message here is aimed at the ethical considerations of such a product or services. So moral appeal in a communication strategy that is influenced by situations in a competitive environment.

\subsection{Diplomacy}

There are certain situations where diplomacy is inevitable. To achieve this, a communicator must package his/her message in such a way. In a competitive environment, the level of diplomacy exhibited can be an added advantage to an organization against other competitors. So diplomatic communication strategy is beneficial in a competitive situation. Therefore situational influence should make the communicator to design a communication that will be diplomatic in nature in order for him/her to achieve set goals.

\subsection{Persuasion}

In a competitive atmosphere, no situation is taken for granted. As a result of this, persuasive messages should be designed to enable set goals to be achieved. When communication is persuasive in nature it enhances productivity. This according to McGuire, (1973: p. 197), "when communication is persuasive it beings about: stimulus-response, cognitive approach, motivational design, social design and personality". So in designing a communication strategy in a competitive environment, persuasion is a strategic tool to achieving set objectives.

\section{Relevance of Communication Strategies in Handling Competition/Competitors}

It is often said that "a bad work man quarrels with his tools". If a communicator does not have a strategic communication skill, he/she will have problem communicating or handling competition/competitors. As a result, aims and objectives would not be realised.

The competitor analysis takes into consideration the competitors' position within the industry and the potential threat it may pose to other businesses. The main purpose of the competitor analysis is for one to analyse both the current and potential nature and capabilities of a competitor in order to prepared against competition. The competitor analysis looks at the following criteria:

\subsection{Identifying competitors}

A business must be able to identify competitors within their industry. Identification of whether competitors provide the same products/services to the same customers. This will be useful in gaining knowledge on direct competitors. Both direct and indirect competitors must identified as well as potential competitors that may enter the market.

\subsection{Assessment of Competitors}

The competitor's analysis looks at the competitors' goals, mission, strategies and resources. This will allow for a thorough comparison of the goals and strategies of both the competitors and organisations.

\subsection{Prediction of Future Initiatives of Competitors}

An early insight into the potential activity of a competitor will help a company be prepared against competition.

Based on the foregoing, it is pertinent for the designer of the communication message to prepare it in such a way as to achieve the objectives of the competitors analysis. As mentioned earlier, a strategic communication message is a weapon for competition. All the different approaches or types of strategic communication principles must be put to use in handling competition/competitors.

When the communication is strategic, it will help objectives to be achieved. This is because the message will 
create understanding among the different competitors. It will woo many competitors into the business market, which will in turn benefit both the manufacturers and the consumers of these goods (products) and services.

Strategic communication helps competition/competitors to be more enterprising. It stimulates business consciousness among competitors.

Another important aspect of communication strategies is that new ideas are generated among competitors. In other words, communication strategies strengthens competition among competitors.

In summary, it is important to note that strategic communication is a vital tool in handling competition/competitors. It is like a search light that helps to direct competitors and shape their undertakings.

\section{Conclusion}

It is quite imperative to note that designing right communication strategy is the best approach in realising tangible results in a competitive environment. Therefore, the communicator must develop communication strategies that can help in packaging the desired message, using the right approach, appropriate words and the necessary media in delivering the message.

In other words, in designing communication strategy, the right approach must be used the prevailing situation must be given adequate consideration, and the intended audience as well.

\section{Recommendations}

Arising from the conclusion above, we make the following recommendations:

1. No situation should be taken for granted when designing any communication strategy.

2. Every situation is very influential. It may create positive or negative impact, and as such any strategy used in communicating messages must take this into consideration.

3. Different communication strategies must be employed when dealing with different competitions and competitors so that the desired result(s) will be attained.

4. Since every situation can possibly influence competition/competitors, designing rightful communication strategies must not be taken for granted. Communicators should know the right approaches to strategic communication.

\section{References}

Bittner, J.R. (1989). Mass Communication: An Introduction. New Jersey: Englewood Cliffs.

Gene, A. (2005), "Frame-worker for Marketing Planning". Michigan Business School.

Liska, J.R. (1978). Situational and Topical Variations in Credibility Criteria. Communication Monograph.

McGuire, W.J. (1973). Persuasion, Resistance and Attitude Change in Handbook of Communication eds.lthiel de Sola Pool et al. Chicago: Rand-McNally.

Munyus, A.W. and Muriuk, M. "Kenya" Global Information Society Watch (GISW). 2009 Report.

Wilson, D. (2005). New Perspectives in Applied Communication. Ibadan: Stirling-Horden Publishers (Nig.) Ltd.

Sambe, J.A. (2008). Introduction to Mass Communication Practice in Nigeria. Ibadan: Spectrum Books Limited. 